\title{
THE STUDY OF DEMOGRAPHIC PROFILE OF CONDUCTION DEFECTS IN ACUTE MYOCARDIAL INFARCTION
}

\author{
Chandrasekar Selvaraj1, Pradeepkumar Mamallan²
}

${ }_{1}^{1}$ Associate Professor, Department of General Medicine, Kilpauk Medical College, Chennai, Tamilnadu, India.

${ }^{2}$ Assistant Professor, Department of General Medicine, Kilpauk Medical College, Chennai, Tamilnadu, India.

ABSTRACT
BACKGROUND
Arrhythmias that develop at the time of acute myocardial infarction, and during its treatment are one of the major causes of death in
a patient with acute coronary syndrome. Acute myocardial infarction is becoming the leading cause of death in developing countries,
more than the infectious diseases. We wanted to study the various conduction defects in myocardial infarction and their
demographic profile in a tertiary care teaching hospital in Kilpauk, Chennai, India.

\section{METHODS}

100 patients with acute myocardial infarction were evaluated from September 18 to December 18, in the age group of 25-90 years, with typical ECG changes, and rise in cardiac enzymes, were included in the study. Those who had pre-existing conduction defects were excluded from the study.

\section{RESULTS}

The incidence of conduction block is around 22\%. Conduction blocks are more common in males and in anteroseptal infarctions. The common age in females are postmenopausal age. Mortality is common in anterior wall than inferior wall MI. The conduction blocks are common in first $24 \mathrm{hrs}$ of hospitalization.

\section{CONCLUSIONS}

The incidence of conduction defects was about $22 \%$ of the total myocardial infarction patients with higher male preponderance. Chest pain is the predominant symptom. In women, it was common in postmenopausal age group. Diabetes and hypercholesterolemia are the commonest comorbid illnesses. AV blocks are common in inferior wall infarction. The most vulnerable period is the first 24 hours. Conduction blocks are common in anterior wall infarction. Complete heart block associated with anterior wall myocardial infarction has the worst prognosis. Thrombolysed patients have increased risk of conduction defects than nonthrombolysed patients. Careful monitoring and prompt treatment of conduction defects and their common complications in a patient with acute myocardial infarction is very important in preventing mortality and morbidity among these patients

HOW TO CITE THIS ARTICLE: Selvaraj C, Mamallan P. The study of demographic profile of conduction defects in acute myocardial infarction. J. Evolution Med. Dent. Sci. 2019;8(18):1455-1458, DOI: 10.14260/jemds/2019/324

\section{BACKGROUND Objective of the Study}

Arrhythmias can complicate the course of patients with both STEMI and NSTEMI, as well as their prevention and treatment. Many arrhythmias develop before hospitalisation and even before patients are monitored. The arrhythmias are divided into tachyarrhythmias and bradyarrhythmia and both can evoke hemodynamic changes in the heart. Myocardial infarctions are the fourth largest cause of death in India. The significant contributor among the cause of death in myocardial infarction is conduction defects ${ }^{1,2}$. The common conduction defects are mainly due to disease per se or it may be due reperfusion arrhythmias. Even though several studies were done in conduction defect in various countries it is parts and so the conduction block pattern were studied in our tertiary care hospital 3,4 .

'Financial or Other Competing Interest': None.

Submission 13-03-2019, Peer Review 17-04-2019,

Acceptance 24-04-2019, Published 06-05-2019.

Corresponding Author:

Pradeepkumar Mamallan,

39/j10, $9^{\text {th }}$ Cross, Mandapam Street,

Madurantakam, Kancheepuram District,

Tamilnadu, India.

E-mail: pradeepmamallan@gmail.com

DOI: $10.14260 /$ jemds $/ 2019 / 324$

To study the various conduction defects in myocardial infarction and its demographic profile in tertiary care teaching hospital.

\section{METHODS}

Study Design

Observation study.

\section{Study Population}

100

\section{Study Period}

October 2017 to December 2018.

100 patients with acute myocardial infarction are evaluated by detailed history, clinical examination. investigations and treatment were obtained and analysed for conduction defects.

\section{Sample Size \\ Sample size was taken for conveniences.}

\section{Inclusion Criteria}

Age group 25 -90 years, with typical ECG changes and rise in cardiac enzymes of acute myocardial infarction were included in the study. 


\section{Exclusion Criteria}

Those who had pre-existing conduction defects were excluded from the study.

\section{Statistical Analysis Tools}

Statistical Package for Social Screening (SPSS), ' $t$ ' test, and Fischer's j exact test, were used to analyse the data.

\section{RESULTS}

The incidence of conduction defects in acute myocardial infarction was $22 \%$. Conduction blocks are more common in males. The commonest presentation was chest pain (95\%) followed by profuse sweating (40\%). Hypercholesterolemia (28.9\%) diabetes $(27 \%)$ and hypertension $(26 \%)$ were the common comorbidities among patients with conduction defects. The incidence of conduction block was more common in acute anteroseptal myocardial infarction (21.1\%) followed by inferior wall myocardial infarction (17.5\%). AV blocks are common in inferior wall infarction. Conduction blocks are common in anterior wall infarction. The commonest arrhythmia is sinus bradycardia. Other common arrhythmias accompanying were ventricular ectopic beats (22\%). The time of appearance of conduction defects was more during the first 24 hours. The incidence of conduction blocks was comparatively higher in thrombolysed patients than the nonthrombolysed ones. Total mortality rate was $7 \%$. Mortality rates were highest among those who had complete heart block. The table 1 shows 1 st degree heart block occurs mostly in the first 24 hours but can occur as late as more than 5 days. The second- and third-degree heart block occurs with much earlier within the first 48 hours of the major incident. Among the ventricular blocks the left anterior hemi block is the commonest one found in 3 persons at the time of admission and the time of presentation is mostly within the first 48 hours and there were no late onset arrhythmias. All type of ventricular arrhythmias is present but RBBB caused mortality among the ventricular arrhythmias. The recovery from ventricular arrhythmias takes long duration than supraventricular tachyarrhythmias.

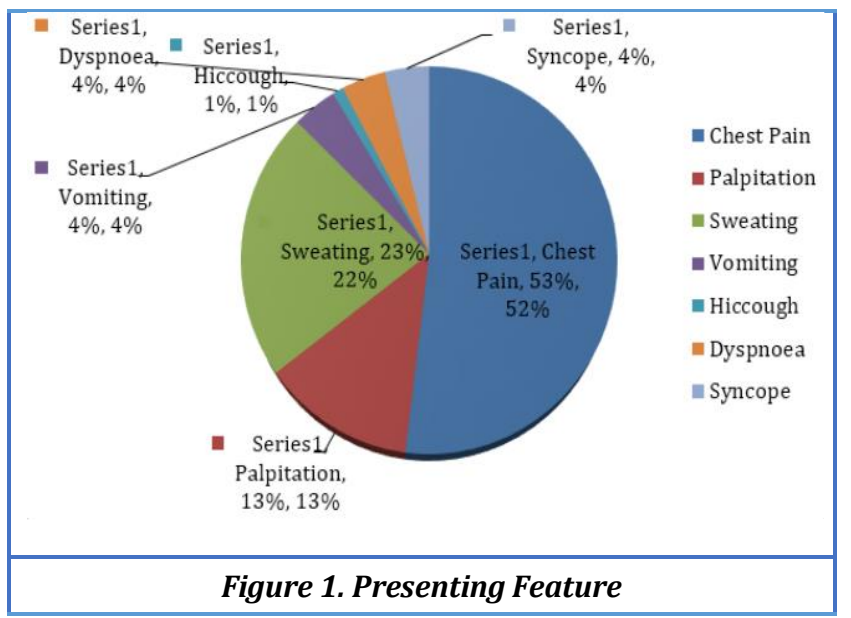

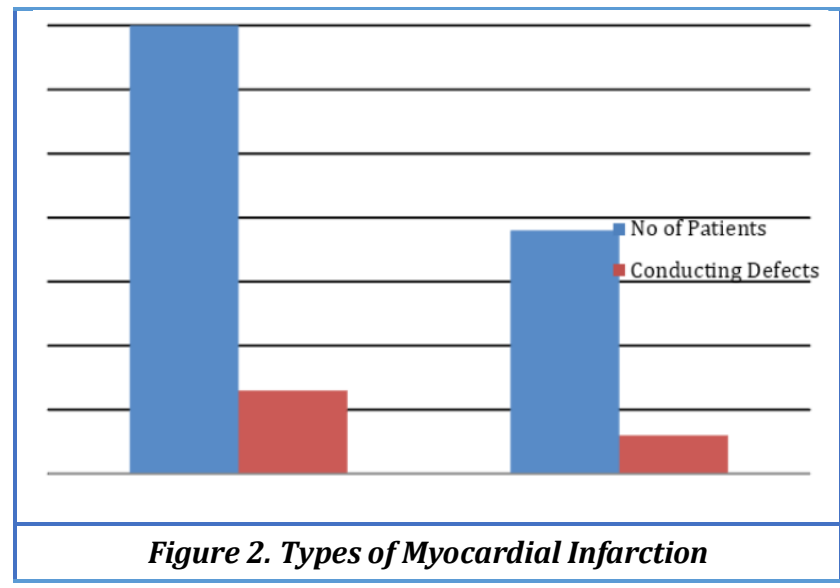

\begin{tabular}{|l|l|l|l|l|}
\hline Time & $\begin{array}{l}\text { On } \\
\text { Admission }\end{array}$ & $\begin{array}{l}\text { 1st 24 } \\
\text { hrs. }\end{array}$ & $\begin{array}{l}\text { 2-5 } \\
\text { days }\end{array}$ & $\begin{array}{l}\text { >5 } \\
\text { days }\end{array}$ \\
\hline AV Block & 2 & 2 & 0 & 1 \\
\hline Ist Degree $^{\mid 5}$ & 1 & 1 & 0 \\
\hline IInd Degree & 1 & 1 & 1 & 0 \\
\hline IIIrd Degree & 0 & 1 & 0 & 0 \\
\hline Intra Ventricular Block & 1 & 1 & 1 & 0 \\
\hline RBBB & 1 & 1 & 1 & 0 \\
\hline LBBB & 3 & 1 & 1 & 0 \\
\hline LAHB & 0 & \multicolumn{5}{|l|}{} \\
\hline LPHB & Relation to The Onset of AMI \\
\hline Table 1. Time of Appearance of Conduction Defects in
\end{tabular}

\section{DISCUSSION}

Myocardial infarction is becoming a major epidemic among the developing countries. The conduction blocks are very common complications encountered during as well as on treatment of myocardial infarction. The major source of conduction blocks being AV node and SA node. Patients with significant reduction in left ventricular function have a relatively fixed stroke volume and heart rate changes the cardiac output. Thus, all forms of brady cardiac and tachycardia can depress the cardiac output. Optimal cardiac output needs heart rate more than hundred for optimum maintenance, it can adversely change the haemodynamics of the heart. In patients with St elevation MI the optimal rate is usually slower in the range of 70 to 80 beats per minute. The second important factor for the changes in the haemodynamics is the loss of atrial contribution to ventricular preload. Certain studies show loss of atrial transport leads to significant reduction in ventricular output by $20 \%$. It assumes more significance in patients with decreased ventricular filling. The cause of conduction block was mainly due to two reasons. First being autonomic failure and second due to ischemic necrosis of the concerned areas. .6 The sinus bradycardia is the commonest type of conduction defect noted in acute myocardial infarction. The widespread use of 
reperfusion therapy and beta blocking agents for the management of STEMI leading to ventricular premature complex, $\mathrm{R}$ on $\mathrm{T}$ phenomenon are predisposing for Ventricular fibrillation were past concept. Accelerated idioventricular rhythm is often observed shortly and typically occur within the first 48 hours. Re-entry caused by inhomogeneity of the electrical activity in the ischemic myocardium is one of the major causes for ventricular tachycardia and ventricular fibrillation. Hypokalaemia also increases the risk of ventricular tachycardia.[18]Early beta blocker prevent the appearance of arrhythmias. Lignocaine prophylaxis for ventricular arrhythmias prevention is no longer advised. Sinus bradycardia commonly occurs in the early phases of STEMI. The increased vagal tone that produces sinus bradycardia during the early STEMI may be beneficial because it reduces myocardial oxygen demand. The acute mortality rate in patients with sinus bradycardia is similar to non-arrhythmia patient. Ischemic injury can cause conduction block both in AV node as well as in intraventricular conduction pathway[15]. Beta blockers and calcium channel antagonists are the common causes for AV delay conduction in ischemic patients. First and second-degree AV blocks do not affect the survival, but it is commonly associated with right coronary artery occlusion.[16] Complete heart block are common in both inferior and anterior wall myocardial infarction but usually progresses from first degree heart block. The escape rhythm is typically stable without asystole and often junctional, with a rate exceeding 40 beats / min.[12] Supraventricular tachycardias are associated with augmented sympathetic activity and increases either hypertension or hypotension. It is common in patients having anterior wall myocardial infarction with accompanying left ventricular dysfunction.[13] Supraventricular tachycardias increases the myocardial oxygen demand and consumption and further increases the myocardial ischaemia. The atrioventricular blocks are common in inferior wall myocardial infarction and bundle branch block are common in the anterior wall myocardial infarction.[14] The conduction blocks are more common than the non-conduction blocks in myocardial infarction. The arrhythmias that occurs due to decreased blood supply to heart are called as ischemic arrhythmias[7] and due to increased blood supply are called reperfusion arrhythmias.[17] The accelerated idioventricular rhythm is the commonest reperfusion arrhythmia encountered during acute management of myocardial infarction especially post thrombolysis. ${ }^{8,9}$

The higher degree AV block showed increased mortality than the other blocks and they are more common in the inferior myocardial infarction. ${ }^{10}$ The primary PCI does not reduce the incidence of mortality in case of higher degree AV block whereas there is a moderate reduction in the firstdegree AV block. The chest pain is still a predominant symptom at presentation but non chest pain symptoms are in rise. The varied presentation does not confer any correlation with the type of conduction blocks. ${ }^{11,10}$

The incidence of ventricular fibrillation with stem has declined drastically over the past decade. Ventricular premature beats with tachycardia is alone treated with beta adrenergic drugs in CAD patients.[19] Other VPB not to be intervened. Due to effective management of arrhythmias the complications have been drastically reduced. Cardioversion remains the mainstay of treatment in patients with unstable ventricular tachycardia and ventricular fibrillation ${ }^{[20]}$ In patients refractory to Cardioversion the amiodarone needs to be continued till recovery. Failure of Cardioversion is commonly caused by recurrent VT/VF. The major mechanism behind being electromechanical dissociation and electrical asystole. Clinical outcomes are bad in patients with VT/VF than those who do not develop. Similarly, the implantable cardiac defibrillator is necessary for the secondary prevention at the time of discharge.

In bradyarrhythmia, the usage of both temporary and permanent pacing is helpful in saving myocardial infarction from death[21]. Complete heart block is the commonest indication for pacing permanently and bifascicular blocks for pacing temporarily. These pacemakers prevent the patients undergoing sudden death. In our study none of the patients had any pacemaker usage and its related complications were not studied. The grave complications due to arrhythmias like pulmonary embolism and left ventricular aneurysm were noted in rare occasions [22]]. In our study one patient developed venous thrombosis and prompt intervention at appropriate time prevented pulmonary embolism. The time of discharge from hospital in patients varied according to type and severity of the arrhythmias. The aggressive reperfusion therapy and PCI has made early discharge possible[23]. In hospital mortality mainly occurs due to pulmonary Congestion, recurrent VT/ VF, new atrial fibrillation and anterior wall myocardial infarction. In our study death due to anterior wall infarction is common than the inferior infarction

\section{CONCLUSIONS}

The incidence of conduction defects was about $22 \%$ of the total myocardial infarction patients with higher male preponderance. Chest pain is the predominant symptom. In women, it was common in postmenopausal age group. Diabetes and hypercholesterolemia are the commonest comorbid illnesses. AV blocks are common in inferior wall infarction. The most vulnerable period is the first 24 hours. Conduction blocks are common in anterior wall infarction. Complete heart block associated with anterior wall myocardial infarction has the worst prognosis. Thrombolysed patients has increased risk of conduction defects than non-thrombolysed patients. Careful monitoring and prompt treatment of conduction defects and their common complications in a patient with acute myocardial infarction is very important in preventing mortality and morbidity among these patients.

\section{REFERENCES}

[1] Sgarbossa EB, Pinski SL, Topol EJ, et al. Acute myocardial infarction and complete bundle branch block at hospital admission: clinical characteristics and outcome in the thrombolytic era. GUSTO-I Investigators. Global Utilization of Streptokinase and t-PA [tissue-type plasminogen activator] for Occluded Coronary Arteries. J Am Coll Cardiol 1998;31(1):105-10.

[2] Shirafkan A, Mehrad M, Gholamrezanezhad A, et al. Conduction disturbances in acute myocardial infarction: a clinical study and brief review of the literature. Hellenic J Cardiol 2009;50(3):179-84.

[3] Ullah I, Ahmad F, Igbal MA, et al. Comparison of conduction abnormalities between anterior and inferior myocardial infarction. Rawal Med J 2005;40:48-51. 
[4] Majumder AA, Malik A, Zafar A. Conduction disturbances in acute myocardial infarction: incidence, site-wise relationship and the influence on in-hospital prognosis. Bangladesh Med Res Counc Bull 1996;22(2):74-80.

[5] Chavda AB, Patel DS, Chatterjee SS. Clinical profile of conduction blocks in patients of acute myocardial infarction at tertiary care hospital, Jamnagar, Gujarat, India. IJSR 2012;1:102-3.

[6] Harper JR, Harley A, Hackel DB, et al. Coronary artery disease and major conduction disturbances. A pathologic study designed to correlate vascular and conduction system abnormalities with electrocardiogram. Am Heart J 1969;77(3):411-22.

[7] Nimetz AA, Shubrooks SJ Jr, Hutter AM Jr, et al. The significance of bundle branch block during acute myocardial infarction. Am Heart J 1975;90(4):439-44.

[8] Nicod P, Gilpin E. Dittrich H, et al. Long-term outcome in patients with inferior myocardial infarction and complete atrioventricular block. J Am Coll Cardiol 1988;12(3):58994.

[9] Xiang L, Zhong A, You T, et al. Prognostic significance of right bundle branch block for patients with acute myocardial infarction: a systematic review and metaanalysis. Medical Science Monitor 2016;22:998-1004.

[10] Baslaib F , Alkaabi S, Yan AT, et al. QRS prolongation in patients with acute coronary syndromes. American Heart Journal 2010;159(4):593-8.

[11] Madias JE, Bravidis D, Attari M. Posterior myocardial infarction and complete right bundle- branch block. Chest 2002;122(5):1860-4.59,[

[12] Harper JR, Harley A, Hackel DB, et al. Coronary artery disease and major conduction disturbances.(593), (2010).

[13] John E. Madias, Demetrius Bravidis and Mehran Attari, Posterior Myocardial Infarction and Complete Right Bundle- Branch Block, Chest, 122, 5, (1860), (2002)

[14] Comparison of the prognostic effect of left versus right versus no bundle branch block on presenting electrocardiogram in acute myocardial infarction patients treated with primary angioplasty in the primary angioplasty in myocardial infarction trials. (PMID:16098297) Guerrero M, Harjai K, Stone GW, Brodie B, Cox D, Boura J, Grines L, O'Neill W, Grines C. Am J Cardiol 2005.
[15] Bandiera A, Rosanio S, Tocchi M, et al. Supraventricular hyperkinetic arrhythmias in acute myocardial infarct: their prognostic assessment and correlation with the echocardiographic evolution. Cardiologia 1994;39:633639. PubMed Google Scholar

[16] Brazdzionyte J, Baksyte G. Risk assessment in acute myocardial infarction. Medicina (Kaunas) 2004;40:121126. Google Scholar

[17] Crimm A, Severance HW, Coffey K, et al. Prognostic significance of isolated sinus tachycardia during first three days of acute myocardial infarction. Am J Med 1984; 76:983-988. PubMed CrossRef Google Scholar

[18] Becker RC, Burns M, Gore JM, et al. Early assessment and in-hospital management of patients with acute myocardial infarction at increased risk for adverse outcomes: a nationwide perspective of current clinical practice. The National Registry of Myocardial Infarction (NRMI-2). Am Heart J 1998;135:786-796

[19] Neumar RW, et al. Part 1: Executive summary 2015 American Heart Association guidelines update for cardiopulmonary resuscitation and emergency cardiovascular care. Circulation. 2015;132(suppl):S315.

[20] Zipes DP, et al. Assessment of the patient with a cardiac arrhythmia. In: Cardiac Electrophysiology: From Cell to Bedside. 6th ed. Philadelphia, Pa.: Saunders Elsevier; 2014. http://www.clinicalkey.com. Accessed Oct. 25, 2015.

[21] Bonow R0, et al. Specific arrhythmias: Diagnosis and treatment. In: Braunwald's Heart Disease: A Textbook of Cardiovascular Medicine. 10th ed. Philadelphia, Pa.: Saunders Elsevier; 2015.

[22] Pederson CT, et al. EHRA/HRS/APHRS expert consensus on ventricular arrhythmias. Heart Rhythm. 2014;11:e166.

[23] Brenyo A, et al. Review of complementary and alternative medicine medical treatment of arrhythmias. The American Journal of Cardiology. 2014;113:897. 